\title{
UMA ANÁLISE CRÍTICA DA DISPENSA E INEXIGIBILIDADE DE LICITAÇÃO - EM BUSCA DE UMA TEORIA QUE POSSIBILITE A APLICAÇÃO A CASOS CONCRETOS
}

\section{A CRITICAL ANALYSIS OF BIDDING EXEMPTION AND UNENFORCEABILITY - IN SEARCH OF A THEORY THAT ALLOWS THE APPLICATION IN SPECIFIC CASES}

\author{
${ }^{1}$ Felipe Cesar Lapa Boselli \\ ${ }^{2}$ Carlos Araújo Leonetti
}

\section{RESUMO}

O artigo tem por objetivo realizar uma análise crítica da legislação, doutrina e jurisprudência acerca das hipóteses de contratação pública sem licitação prévia, trabalhando em uma teoria para divisão dos institutos existentes e aplicando essa teoria na hipótese central do artigo de que seria ilícita a contratação emergencial de serviços contínuos, por meio de dispensa de licitação. O método de pesquisa adotado foi o bibliográfico.

Palavras-chave: Direito administrativo, Licitação, Dispensa, Inexigibilidade

\section{ABSTRACT}

The paper aims to conduct a review of the legislation, doctrine and jurisprudence about the possibilities of public hiring without bidding, working on a theory for division of existing institutes and applying this theory in the central hypothesis of the article that it would be illegal to emergency hiring continuous service through the bidding process.

Keywords: Administrative law, Bidding, Exemption, Unenforceability

\footnotetext{
${ }^{1}$ Doutorando em Direito do Estado pela Universidade Federal de Santa Catarina - UFSC, Santa Catarina (Brasil). Professor convidado dos Cursos de Pós-Graduação da Universidade do Sul de Santa Catarina - UNISUL, Santa Catarina (Brasil). E-mail: felipeboselli1986@hotmail.com

${ }^{2}$ Doutor em Direito do Estado pela Universidade Federal de Santa Catarina - UFSC, Santa Catarina (Brasil). Professor da Universidade Federal de Santa Catarina - UFSC, Santa Catarina (Brasil). E-mail: cleonetti37@gmail.com
} 


\section{INTRODUÇÃO}

O objetivo do presente artigo e apresentar um estudo crítico das hipóteses legais de contratação, pelo Poder Público, sem licitação prévia.

Para tal, procurar-se-á responder ao seguinte problema: e possível desenvolverse uma teoria que permita, em casos práticos, distinguir-se hipóteses de dispensa e de inexigibilidade de licitação?

Os temas centrais abordados consistem no conceito e histórico de licitação no direito brasileiro e os conceitos e distinções de dispensa e de inexigibilidade.

Desde 1988, com o advento da Constituição, a realização de processos licitatórios passou de mera atividade burocrática estatal-organizacional a um status de mandamento constitucional.

Em seu artigo 37, que trata da organização da Administração Pública e seus princípios o constituinte optou por sacramentar a regra geral da licitação, estabelecendo que, exceto nos casos especificados na legislação, todas as obras, serviços, compras e alienações serão precedidas de processo licitatório.

Nota-se que o constituinte original determinou o processo de licitação como regra geral a ser seguida em todas as contratações públicas, já estabelecendo obrigações gerais que seriam, futuramente, disciplinadas pela legislação infraconstitucional.

Do referido dispositivo, para o estudo que aqui se desenvolve, é importante destacar o início do dispositivo que possibilita a hipótese da legislação ressalvar determinados casos, nos quais a Administração estaria desobrigada de realizar o processo licitatório.

De plano, é fundamental destacar um equívoco ou, ao menos, uma imprecisão no texto constitucional que fez uma única ressalva às contratações por licitação, sendo esta as situações que foram expressamente previstas pela legislação infraconstitucional. Como será abordado adiante, esta não é, e nem poderia ser, a única ressalva à contratação sem processo licitatório.

Com a criação da Lei $n^{\circ}$ 8.666/93, foram criadas as hipóteses de contratação sem licitação, divididas em três subcategorias: a) licitações dispensadas (artigo 17); b) licitações dispensáveis (artigo 24); e c) inexigibilidade de licitação (artigo 25). Por uma questão de coerência metodológica e maior clareza na compreensão dos conceitos, serão abordados primeiramente as duas últimas (artigos 24 e 25) para depois apresentar as licitações dispensadas. 
Na sequência, valendo-se do método dedutivo, utilizando do levantamento bibliográfico e jurisprudencial com uma análise crítica, será apresentada a confusão existente entre os institutos da licitação dispensável e da inexigibilidade, para então chegar à discussão que se pretende com o presente artigo.

\section{AS LICITAÇÕES DISPENSÁVEIS: O ARTIGO 24 DA LEI No 8.666/93}

Dentre as hipóteses de contratação sem licitação a mais comum são, sem dúvida, as licitações dispensáveis, previstas no artigo 24 da Lei n 8.666/93.

$\mathrm{O}$ artigo 24, até o momento da elaboração do presente estudo, possui 34 (trinta e quatro) hipóteses nas quais o legislador autorizou dispensar a licitação.

Este é o conceito fundamental da dispensa de licitação: trata-se, como se observa da própria nomenclatura utilizada, de possibilidades nas quais o legislador infraconstitucional, por alguma motivação específica, permitiu ao gestor público o descumprimento do mandamento constitucional de se realizar o processo licitatório em todas as contratações públicas.

Este conceito da licitação dispensável possibilita ao intérprete duas conclusões imediatas e fundamentais: a) a dispensa deve ser uma lista restritiva; e b) deve haver uma motivação para que seja elaborada lei autorizando a dispensa. Explica-se:

O primeiro conceito é mais simples e será o mais importante ao presente estudo. Se a Constituição estabeleceu a obrigatoriedade de se realizar o processo licitatório, o gestor público somente estará autorizado a realizar a contratação afastando a licitação nas hipóteses em que for expressamente autorizado pelo legislativo. Este conceito é, de certa forma, básico e está claramente expresso no caput do artigo 24 da Lei no 8.666/93: “Art. 24. É dispensável a licitação”.

Nota-se que o legislador, claramente, utilizou uma redação que permite inferir que a lista de incisos que seguirá o caput será uma lista restritiva, impossibilitando, portanto, interpretações extensivas, analogias ou ampliações de qualquer gênero. Nem poderia ser diferente. Há que se lembrar que ao afastar o processo licitatório o gestor público está deixando de atender ao mandamento constitucional e só poderia fazê-lo nas hipóteses em que for expressamente autorizado pelo legislador.

Deste conceito se desdobra a segunda ideia das dispensas de licitação: a questão da motivação para que o legislador infraconstitucional crie hipótese de licitação dispensável. 
É fato que, ao insculpir a regra do processo licitatório, o constituinte criou ao legislador ordinário a possibilidade de ressalvar esta regra licitatória com exceções. Contudo, isso não significa, em absoluto, uma liberdade total e irrestrita na criação de hipóteses que afastam a imposição constitucional.

Em suma: será considerada inconstitucional a lei ordinária que criar exceção à regra licitatória, contrariando o estabelecido o inciso XXI do artigo 37 da Constituição? Certamente que não, diante da admissibilidade de tais hipóteses no próprio texto constitucional. Contudo, isso não significa, sob nenhum aspecto, que toda e qualquer norma que afaste o processo licitatório seria considerada constitucional. Há sim que se realizar juízo material acerca da validade jurídica de norma exceptuadora da regra licitatória sob pena de se conferir poder ao legislador infraconstitucional para revogar uma regra constitucional. Por exemplo, qualquer um entenderia inconstitucional a lei ordinária que estabelecesse que, a partir de hoje, todas as contratações públicas seriam realizadas sem licitação, criando hipótese de dispensa genérica, geral e irrestrita.

Não há dúvida, portanto, que a norma criadora de dispensa de licitação deve estar dotada de justificativa jurídica, econômica, técnica ou fática que fundamente a criação de norma capaz de excetuar o mandamento constitucional.

A licitação dispensável pode ser caracterizada, portanto, pela hipótese na qual o legislador autorizou o gestor público a não realizar o processo licitatório, isso não significa, entretanto, que o gestor está proibido de realizar o certame. É, sim, uma faculdade de afastar a licitação, quando isso for do interesse público, portanto, que pode ser utilizada ou não, como ensina GASPARINI (2008, p. 520).

\section{A INEXIGIBILIDADE DE LICITAÇÃO: O ARTIGO 25 DA LEI N 8.666/93}

Definidos os contornos jurídicos da dispensa de licitação é possível compreender as características da inexigibilidade. A expressão inexigibilidade foi cunhada a partir do texto adotado no caput do artigo 25 , que assim estabelece:

Art. 25. É inexigível a licitação quando houver inviabilidade de competição, em especial:

I - para aquisição de materiais, equipamentos, ou gêneros que só possam ser fornecidos por produtor, empresa ou representante comercial exclusivo, vedada a preferência de marca, devendo a comprovação de exclusividade ser feita através de atestado fornecido pelo órgão de registro do comércio do 
local em que se realizaria a licitação ou a obra ou o serviço, pelo Sindicato, Federação ou Confederação Patronal, ou, ainda, pelas entidades equivalentes; II - para a contratação de serviços técnicos enumerados no art. 13 desta Lei, de natureza singular, com profissionais ou empresas de notória especialização, vedada a inexigibilidade para serviços de publicidade e divulgação;

III - para contratação de profissional de qualquer setor artístico, diretamente ou através de empresário exclusivo, desde que consagrado pela crítica especializada ou pela opinião pública.

Tem-se, portanto, dois institutos absolutamente distintos: enquanto a inexigibilidade se caracteriza pela inviabilidade de competição, o que significa dizer que é impossível a realização da licitação, a licitação dispensável é, como já visto, a faculdade concedida pelo legislador, autorizando a contratação sem certame prévio.

A inexigibilidade de licitação é um instituto fático, não jurídico. Trata-se da inviabilidade mundana de se atender ao comando constitucional que determina a obrigatoriedade da licitação. Fato é que, ainda que o constituinte queira que todos os contratos sejam licitados, a realidade dos fatos, em alguns casos, não permite o processo licitatório prévio.

Aqui reside o núcleo fundamental da licitação inexigível, trata-se de hipótese na qual é inviável a competição (CITADINI, 1997, p. 188). Contudo, este texto, insculpido na legislação geral, permite uma conclusão equivocada, que confunde a inexigibilidade de licitação com a exclusividade de fornecimento.

Será inexigível a licitação quando não for possível realizar a competição entre atores que busquem aquela determinada contratação. Não há dúvida que a existência de um único contratado possível (exclusividade de fornecimento) é uma hipótese de inviabilidade de competição, que se traduz em sua forma mais óbvia: como não existem competidores, não existe competição. Este conceito primário da inexigibilidade é comumente compreendido pelos gestores públicos e operadores desses processos em geral.

Ocorre que a inexigibilidade de licitação não se resume à hipótese de existir um único competidor no mercado, mas é aplicável a todas as situações nas quais restar evidenciado que não é possível promover a competição.

Evidentemente, o conceito de competição trazido pelo legislador deve ser pensado em uma visão sistêmica da legislação como um todo. É um equívoco comum 
fazer a leitura do dispositivo sob o ponto de vista mercadológico, da inexistência de competição por monopólio.

Contudo, não é este o conceito adotado pelo legislador. Ao conceituar a inviabilidade de competição na lei de licitações deve-se ter em mente a ideia de competição seguindo os regramentos definidos pela mesma legislação, sobretudo no que tange ao artigo $3^{\circ}$ da Lei $n^{\circ} 8.666 / 93$ :

\begin{abstract}
Art. $3^{\circ}$ A licitação destina-se a garantir a observância do princípio constitucional da isonomia, a seleção da proposta mais vantajosa para a administração e a promoção do desenvolvimento nacional sustentável e será processada e julgada em estrita conformidade com os princípios básicos da legalidade, da impessoalidade, da moralidade, da igualdade, da publicidade, da probidade administrativa, da vinculação ao instrumento convocatório, do julgamento objetivo e dos que lhes são correlatos.
\end{abstract}

Logo o termo "inviabilidade de competição" utilizado pelo legislador deve ser interpretado como a inviabilidade de realização de processo licitatório, posto que é neste formato que se adota a competição para a realização de contratos administrativos.

Para se considerar se é viável a realização de processo licitatório, certamente, não deve ser observado apenas o volume de competidores existente no mercado, mas também, se é possível realizar um processo licitatório, em conformidade com as regras estabelecidas pela legislação, para uma determinada situação concreta.

Como afirmado anteriormente, a inexigibilidade de licitação é um instituto fático. São os contornos da situação real que delimitam se é cabível, ou não, a inexigibilidade de licitação. Em suma, qualquer situação concreta em que for inviável a competição estará caracterizada a inexigibilidade. Nas palavras de PEREIRA JÚNIOR (2009, p. 343): “O leque de situações em que se apresenta tal impossibilidade é largo e variado, por vezes surpreendente [...]”.

Um dos exemplos de situação fática que não viabiliza a competição por meio de processo licitatório é a hipótese de contratação de atividades cujo critério para contratação é eminentemente subjetivo.

A impossibilidade de se adotar critérios objetivos para a contratação de um determinado objeto impede a consecução do princípio do julgamento objetivo e, consequentemente, inviabiliza a própria realização de uma competição via processo licitatório. 
Não existe licitação com critérios subjetivos, o processo licitatório depende, intimamente, de um sistema absolutamente objetivo que permita comparar propostas a serem apresentadas de forma totalmente técnica e imparcial, garantindo o princípio constitucional da isonomia, objetivo primário da realização do certame público.

Assim sendo, nas contratações em que não existe a possibilidade de se realizar uma competição que adote critérios objetivos, está caracterizada a inviabilidade de competição formulada no caput do artigo 25 , tornando a licitação inexigível e, portanto, lícita a contratação sem processo licitatório prévio.

O próprio legislador demonstra a aplicabilidade desse raciocínio ao adotar dois exemplos que se enquadram na situação ora descrita. São os incisos II e III do artigo 25 da Lei 8.666/93.

Dos três exemplos utilizados pela Lei de Licitações, dois pertencem à categoria da inviabilidade de competição em razão da inexistência de critério objetivos que permitam o cotejamento das propostas. São eles: a) serviços técnicos singulares com profissionais de notória especialização (inciso II) e; b) contratação de artistas (inciso III).

Fato é que as duas possibilidades trazidas pelo legislador nos incisos II e III do artigo 25 demonstram bem a inviabilidade de competição em razão da ausência de critérios objetivos. Se tomada a contratação de artistas como exemplo, não há dúvida que existe uma pluralidade de competidores no mercado, mas não é possível, com a atual legislação de licitações, cotejar propostas para selecionar o artista que se apresentará em um evento público.

Nota-se que o conceito por trás da inexigibilidade de licitação é a impossibilidade de se realizar a competição por questões fáticas, o que independe de autorização legal e nem poderia depender, posto que a realidade pode inviabilizar o processo licitatório por inúmeros motivos, como se verá adiante.

\section{A LICITAÇÃO DISPENSADA: O ARTIGO 17 DA LEI Nº 8.666/93}

Ainda que não seja o escopo do presente artigo, cabe explicar o conceito da licitação dispensada, classificada por doutrinadores como uma terceira via para não realizar o processo licitatório. Em verdade, como será demonstrado, a licitação dispensada nada mais é do que uma inexigibilidade de licitação que o legislador optou por criar um rol de possibilidades. 
Nem haveria alternativa a isso. A Constituição determina expressamente que o processo licitatório é regra para todas as contratações públicas ressalvadas as hipóteses previstas em lei. Ou seja, só existem duas situações em que será feita uma contratação sem processo licitatório: a) quando a lei autoriza expressamente (dispensa); e b) quando, por questões fáticas, é impossível cumprir o mandamento constitucional (inexigibilidade).

Assim, em uma análise crítica, não dogmática, da legislação é possível perceber que o próprio legislador se equivocou em diversos momentos na redação da Lei $n^{\circ} 8.666 / 93$. Um desses equívocos está no seu artigo 17:

Art. 17. A alienação de bens da Administração Pública, subordinada à existência de interesse público devidamente justificado, será precedida de avaliação e obedecerá às seguintes normas:

I - quando imóveis, dependerá de autorização legislativa para órgãos da administração direta e entidades autárquicas e fundacionais, e, para todos, inclusive as entidades paraestatais, dependerá de avaliação prévia e de licitação na modalidade de concorrência, dispensada esta nos seguintes casos: a) dação em pagamento;

b) doação, permitida exclusivamente para outro órgão ou entidade da administração pública, de qualquer esfera de governo, ressalvado o disposto nas alíneas $\mathrm{f}$, h e i;

c) permuta, por outro imóvel que atenda aos requisitos constantes do inciso $\mathrm{X}$ do art. 24 desta Lei;

d) investidura;

e) venda a outro órgão ou entidade da administração pública, de qualquer esfera de governo;

f) alienação gratuita ou onerosa, aforamento, concessão de direito real de uso, locação ou permissão de uso de bens imóveis residenciais construídos, destinados ou efetivamente utilizados no âmbito de programas habitacionais ou de regularização fundiária de interesse social desenvolvidos por órgãos ou entidades da administração pública;

g) procedimentos de legitimação de posse de que trata o art. 29 da Lei ${ }^{\circ}$ 6.383, de 7 de dezembro de 1976, mediante iniciativa e deliberação dos órgãos da Administração Pública em cuja competência legal inclua-se tal atribuição;

h) alienação gratuita ou onerosa, aforamento, concessão de direito real de uso, locação ou permissão de uso de bens imóveis de uso comercial de âmbito local com área de até $250 \mathrm{~m}^{2}$ (duzentos e cinqüienta metros quadrados) 
e inseridos no âmbito de programas de regularização fundiária de interesse social desenvolvidos por órgãos ou entidades da administração pública;

i) alienação e concessão de direito real de uso, gratuita ou onerosa, de terras públicas rurais da União na Amazônia Legal onde incidam ocupações até o limite de 15 (quinze) módulos fiscais ou 1.500ha (mil e quinhentos hectares), para fins de regularização fundiária, atendidos os requisitos legais;

II - quando móveis, dependerá de avaliação prévia e de licitação, dispensada esta nos seguintes casos:

a) doação, permitida exclusivamente para fins e uso de interesse social, após avaliação de sua oportunidade e conveniência sócio-econômica, relativamente à escolha de outra forma de alienação;

b) permuta, permitida exclusivamente entre órgãos ou entidades da Administração Pública;

c) venda de ações, que poderão ser negociadas em bolsa, observada a legislação específica;

d) venda de títulos, na forma da legislação pertinente;

e) venda de bens produzidos ou comercializados por órgãos ou entidades da Administração Pública, em virtude de suas finalidades;

f) venda de materiais e equipamentos para outros órgãos ou entidades da Administração Pública, sem utilização previsível por quem deles dispõe.

Do dispositivo supramencionado, mesmo em uma análise superficial, é facilmente constatado que tratam, na verdade, de situações nas quais seria impossível realizar a licitação, sendo, portanto, hipóteses de inexigibilidade.

Veja-se, como exemplo, a alínea a do inciso I, dispensando a licitação para a dação em pagamento. Ora, se a Administração pretende utilizar um imóvel para quitar uma determinada dívida, não há o que falar em processo licitatório. A dívida é exclusiva de um determinado agente e, portanto, a dação em pagamento somente pode ser realizada entre o Estado devedor e o credor unitário. Não há como se realizar competição nesses casos. O mesmo ocorre na doação interna de bens imóveis na estrutura da Administração Pública. Se, para atender a uma determinada demanda, um órgão pretende doar um imóvel a outro órgão público, também não há como realizar processo licitatório com essa finalidade.

Também no inciso II, para a alienação de bens móveis, o raciocínio se repete. Tome-se como exemplo a alínea c, que trata da alienação de ações, feita na forma da legislação específica, negociada em bolsa. Não existe outra forma de se comercializar ações, não há como realizar processo licitatório para que a Administração venda esse tipo de papel. 
Por não ser o objetivo central do presente artigo, não há porque alonga-lo além do necessário, explicando item a item, mas é fato que todos os casos previstos no artigo 17, denominados pela legislação de licitação dispensada, possuem o mesmo contorno de inviabilidade de competição e, consequentemente, de inexigibilidade de licitação e seriam tranquilamente contemplados no caput do artigo 25 com a devida justificativa fática.

\title{
5. A CONFUSÃO ENTRE LICITAÇÃO DISPENSÁVEL E INEXIGIBILIDADE DE LICITAÇÃO.
}

Após o esclarecimento de cada um dos três institutos criados pela Lei $n^{\circ}$ 8.666/93 e, principalmente, com a discussão e demonstração que, na verdade, existem dois fundamentos para a contratação sem licitação: a) autorização legal (licitação dispensável); e b) inviabilidade fática (inexigibilidade), fica possível fazer uma análise crítica da legislação e jurisprudência do tema.

Como já visto, a própria legislação confunde os conceitos de licitação dispensável e inexigibilidade de licitação ao criar o que aparentaria ser uma terceira possibilidade (licitação dispensada), cuja nomenclatura aproxima da licitação dispensável, embora seja categoria totalmente diversa e que, em verdade se enquadra no conceito teórico da inexigibilidade.

Diversos autores ${ }^{1}$ apontam a licitação dispensável (artigo 24) e a licitação dispensada (artigo 17) como duas espécies de uma mesma categoria, como afirmam MOREIRA e GUIMARÃES (2012, p. 404):

\begin{abstract}
A contratação direta poderá resultar tanto das hipóteses de dispensa - o que pressupõe o enquadramento da situação fática em uma das hipóteses tipificadas (exaustivamente) pelos arts. 24 e 17 da LGL - -como da inexigibilidade de licitação - quando houver inviabilidade de competição, nos termos do art. 25 da mesma lei.
\end{abstract}

Essa confusão permanece, de forma ainda mais clara, em diversos incisos do artigo 24. É exemplo dessa confusão o inciso X do artigo 24, que assim disciplina:

1 Também classificam conjuntamente a licitação dispensada e a licitação dispensável autores como: MELLO (2002, p. 498), FURTADO (2010 p. 61) ou NIEBUHR (2011, p. 207). 
$\mathrm{X}$ - para a compra ou locação de imóvel destinado ao atendimento das finalidades precípuas da administração, cujas necessidades de instalação e localização condicionem a sua escolha, desde que o preço seja compatível com o valor de mercado, segundo avaliação prévia;

O dispositivo legal, largamente utilizado na Administração Pública para locação de imóveis, é um claro equívoco legislativo. Ao aplicar no dispositivo os conceitos fundamentais da licitação dispensável, nota-se que o dispositivo não se sustenta teoricamente.

$\mathrm{O}$ inciso $\mathrm{X}$ é claro ao condicionar a possibilidade da dispensa aos imóveis “cujas necessidades de instalação e de localização condicionem a sua escolha”. Se as necessidades da Administração condicionaram a escolha a um único imóvel possível, por conseguinte, não existe uma pluralidade de opções a serem escolhidas, capazes de serem comparadas objetivamente por meio de processo licitatório, não há aqui faculdade legislativa de se afastar a licitação, mas sim impedimento fático de se realizar o certame, sob pena de criar-se um pretenso certame, uma licitação simulada, que em nada atenderia o mandamento constitucional.

O mesmo conceito se aplicaria ao inciso XII:

XII - nas compras de hortifrutigranjeiros, pão e outros gêneros perecíveis, no tempo necessário para a realização dos processos licitatórios correspondentes, realizadas diretamente com base no preço do dia;

A dispensa prevista no inciso XII do artigo 24 da Lei 8.666/93, faculta o gestor público a comprar produtos perecíveis enquanto não for concluído o processo licitatório. Ora, em se tratando de produtos que não podem ser armazenados até a conclusão do processo licitatório, tem-se evidente hipótese de inexigibilidade, na qual o administrador não tem a opção de contratar com licitação, visto que a licitação já está em andamento mas ainda não foi concluída, em um momento que o estoque precisa ser reabastecido de imediato, como também entende MOTTA (2005, p. 223).

Trata-se de inviabilidade fática de realizar o processo licitatório em decorrência da questão temporal. O momento não permite realizar licitação, visto que o processo já está aberto e não será concluído em tempo hábil para atender às necessidades da Administração.

Este conceito será fundamental no capítulo seguinte, na análise crítica que se pretende formatar sobre a jurisprudência e doutrina pátria. 
Também poderia ser usado como exemplo para demonstrar a confusão aqui citada, o inciso XVIII:

\begin{abstract}
XVIII - nas compras ou contratações de serviços para o abastecimento de navios, embarcações, unidades aéreas ou tropas e seus meios de deslocamento quando em estada eventual de curta duração em portos, aeroportos ou localidades diferentes de suas sedes, por motivo de movimentação operacional ou de adestramento, quando a exiguidade dos prazos legais puder comprometer a normalidade e os propósitos das operações e desde que seu valor não exceda ao limite previsto na alínea "a" do inciso II do art. 23 desta Lei;
\end{abstract}

O legislador facultou às Forças Armadas a possibilidade de abastecer seus veículos fora das respectivas sedes, quando em movimentação operacional, nos casos em que o prazo puder comprometer a normalidade das operações.

De novo, tem-se hipótese evidente de inviabilidade de competição por razão geográfico-temporal. É óbvio que não seria possível interromper a movimentação de veículos militares em operação para que se aguardasse alguns meses até a conclusão do processo licitatório para aquisição de combustível. Não há nenhuma dúvida que a hipótese prevista pelo legislador inviabiliza a competição licitatória e, portanto, a contratação sem licitação não é uma faculdade, mas sim uma imposição fática.

Mais ainda, nota-se que o legislador se equivoca duplamente, ao limitar a possibilidade de contratação sem licitação ao valor de $\mathrm{R} \$ 80.000,00$ (oitenta mil reais) nestes casos.

A lei não tem o condão de modificar a realidade. Se, durante uma movimentação de tropas militares, for imprescindível a imediata aquisição produtos para o abastecimento de um valor maior que os $\mathrm{R} \$ 80.000,00$, para concluir uma operação essencial, as Forças Armadas vão interromper o trajeto por meses até concluir o processo licitatório para a compra do combustível? Por evidente que não.

A hipótese é de inexigibilidade e, por isso, não detém os mesmos contornos da licitação dispensável, incluindo aqui as limitações legais naturais às faculdades concedidas pelo legislador. Em sendo a contratação inexigível, pela inviabilidade fática de competição licitatória, não é possível que o legislador trace limites à realidade.

Fato é que são diversos os incisos do artigo 24 que, em maior ou menor grau, confundem os conceitos de licitação dispensável e de inexigibilidade de licitação, o que 
reflete, sobremaneira, para que a jurisprudência e doutrina pátria também tratem os dois institutos a esmo, sem uma teoria distintiva precisa e clara.

\section{A QUESTÃO EM DEBATE}

Realizadas as devidas conceituações, resta a pergunta central do presente artigo: é cabível a contratação emergencial de serviços contínuos nos casos em que o processo licitatório não foi concluído antes do encerramento do contrato anterior?

É o caso em que se tem um contrato administrativo para execução de um serviço contínuo, essencial às atividades de determinado órgão, no qual o processo licitatório para a escolha do próximo contratado, por qualquer motivo, não pôde ser concluído antes de expirado, por completo, o prazo contratual.

Não se busca discutir aqui as causas que levaram à não conclusão tempestiva do certame licitatório e à concepção do novo contratado, talvez seja a desídia dos gestores, a falta de planejamento, discussões jurídicas, a suspensão do processo pelos órgãos de controle, a falta de interessados no certame ou qualquer outro motivo.

O que se debate aqui é a consequência jurídica da não conclusão do certame a tempo ou, melhor dizendo, como será solucionado o problema da falta de um contratado para a execução daquelas atividades que são essenciais. A doutrina e jurisprudência pátria apresenta como solução para este caso a hipótese de dispensa prevista no artigo 24, inciso IV da Lei $n^{\circ} 8.666 / 93$, os chamados

casos de emergência:

IV - nos casos de emergência ou de calamidade pública, quando caracterizada urgência de atendimento de situação que possa ocasionar prejuízo ou comprometer a segurança de pessoas, obras, serviços, equipamentos e outros bens, públicos ou particulares, e somente para os bens necessários ao atendimento da situação emergencial ou calamitosa e para as parcelas de obras e serviços que possam ser concluídas no prazo máximo de 180 (cento e oitenta) dias consecutivos e ininterruptos, contados da ocorrência da emergência ou calamidade, vedada a prorrogação dos respectivos contratos;

Antes de analisar a aplicabilidade ou não do referido dispositivo legal à questão em debate, é interessante aplicar a teoria formulada nos capítulos precedentes para checar a adequação do dispositivo legal à regra.

$\mathrm{O}$ inciso IV trata da faculdade de afastar o processo licitatório nos casos em que a atividade é emergencial e possa ser concluída em até 180 dias contados da 
emergência, vedada a prorrogação desse contrato cuja licitação foi dispensada. O conceito de dispensa é perfeitamente aplicável a este dispositivo, sendo a hipótese legal uma faculdade concedida pelo legislador (é perfeitamente possível que se faça licitação nesses casos) e que possui uma motivação (o tempo de espera do certame certamente prejudicaria o atendimento emergencial, nos casos de atividades que possam ser concluídas em 180 dias contados da emergência).

Testada a regra teórica e visto que se tem caso de licitação dispensável, e não de inexigibilidade de licitação, travestida de dispensa, é necessário ao operador jurídico utilizar os mecanismos específicos da licitação dispensável ao adotar o inciso IV do artigo 24 no caso concreto.

Para isso, o processo de subsunção da norma deve ser absolutamente escorreito, sem analogias, interpretações extensivas ou ampliações no processo interpretativo. A dispensa, por ser uma autorização legal, prescinde da exatidão ao unir o dever ser da norma e o ser do fato que se pretende enquadrar na norma. Caso contrário, não cabe a hipótese de dispensa, posto que, àquele caso concreto, não foi dada autorização legal para afastar o mandamento constitucional.

O tema em debate não permite essa aplicação direta e inequívoca do dispositivo. O legislador foi claro ao facultar a dispensa exclusivamente aos "serviçosque possam ser concluídas no prazo máximo de 180 (cento e oitenta) dias consecutivos e ininterruptos, contados da ocorrência da emergência ou calamidade”.

Note-se que o legislador demanda a conclusão dos serviços em 180 dias. Este mandamento por si só, já seria suficiente para afastar a aplicação do dispositivo ao caso. Os serviços contínuos, como se observa de sua nomenclatura são continuados, infinitos, inconclusos, não terminam nunca. As atividades de limpeza, de vigilância, de manutenção, dentre outras não serão concluídas em 180 dias, esses serviços jamais são finalizados, sendo sua demanda uma constante. Não obstante, é pacífica sua admissibilidade pela jurisprudência:

\footnotetext{
Admite-se, em caráter excepcional, e com fundamento no interesse público, contratação emergencial da prestação de serviços que não possam sofrer solução de continuidade, desde que justificada adequadamente no respectivo processo e apontados os problemas que poderão advir da paralisação de tais serviços, comprovando-se a ocorrência de prejuízo ao interesse público, a contratação será apenas durante o prazo necessário para a realização do novo processo licitatório, observando-se o disposto no art. 26 da Lei ${ }^{\circ}$ 8.666/1993.
} (BRASIL, 2009) 
A solução prática a esta questão é a assinatura de contratos que possuem vigência de 180 dias. O equívoco é evidente. Ainda que pudesse ser confundida a conclusão dos serviços com o prazo de vigência do contrato, o termo inicial para a contagem do prazo legal é a data da emergência, não a data da assinatura do contrato ou a data da emissão da ordem serviço.

Se o termo inicial é a data da emergência, resta claro que o prazo e vigência de um contrato firmado com fulcro no artigo 24, IV jamais poderia ter 180 dias de vigência, isto porque existem procedimentos prévios à assinatura do contrato, tais como a redação do contrato em si, a localização do possível contratado, a concepção da atividade que será realizada, dentre outros.

Mesmo assim, em uma interpretação muito mais do que extensiva, chega-se à ideia de que o legislador teria permitido aquilo que nunca permitiu e, com isso, se autoriza a contratação emergencial de serviços contínuos, desde que o contrato possua vigência de até 180 dias.

Ocorre que, firmado esse instrumento contratual, a prática pode apresentar ainda um outro problema. É o caso de a licitação não ser concluída até o término dos 180 dias, quando se encerra o contrato emergencial. Novamente, não se discute os motivos que levaram a esse cenário, mas sim a solução desse problema.

O raciocínio natural seria a prorrogação do contrato emergencial, posto que persiste a situação fática que fundamentou a emergência. Contudo, o legislador, ao facultar a dispensa neste caso, ao contrário, vedou expressamente a prorrogação dos respectivos contratos.

Em sendo vedada a prorrogação dos contratos emergenciais ${ }^{2}$, a solução ao caso costuma ser uma espécie de disfarce na prorrogação, por exemplo, com a realização de um novo processo de dispensa, para uma nova contratação com o mesmo objeto, o mesmo prazo e com as mesmas partes. Sobre o tema comenta NIEBUHR (2011, p. 253254):

Por exemplo, diante de situação de emergência, a Administração firma contrato com fulcro no inciso IV do artigo 24 da Lei $n^{\circ} 8.666 / 93$, cujo prazo de duração é de 180 (cento e oitenta) dias. A partir de então, a Administração, imediatamente, dá início à licitação, que, todavia, é suspensa por decisão prolatada por juiz de Direito, em vista de ação judicial proposta por um dos licitantes. Então, por força de decisão judicial, a Administração é impedida de concluir a licitação no prazo de 180 (cento e oitenta) dias. O contrato outrora firmado com dispensa está preste a se encerrar, sem que se 
possa prorroga-lo e sem que a licitação tivesse sido concluída. Essa situação poderia deitar a perder o interesse público, já que, em princípio, a Administração ficaria sem a utilidade recebida mediante o contrato, que não pode ser prorrogado. Sem embargo, perceba-se que o legislador proibiu apenas a prorrogação, não a celebração de novo contrato amparado pelo mesmo dispositivo, ainda que regido pelas mesmas cláusulas e celebrado com o mesmo contratado antecedente. Daí que, para proteger o interesse público, em vez de prorrogar o contrato antecedente. Daí que, para proteger o interesse público, em vez de prorrogar o contrato, é lícito celebrar um novo, não importa se idêntico ao que lhe antecedeu.

Ora, ainda que seja feito novo processo de dispensa, não há dúvida que se está diante de uma prorrogação contratual com outra nomenclatura.

Fato é que são diversos os fundamentos que demonstram a inaplicabilidade da dispensa por emergência para a contratação de serviços contínuos. A justificativa de que não seria possível outra forma de contratação e nem ficar sem a prestação daquele serviço não é o fundamento da licitação dispensável e, portanto, não poderia ser utilizada. Em não havendo autorização legal para afastar o processo licitatório, a dispensa é ilegal.

Exemplo interessante neste sentido é a imposição de uma ordem judicial, suspendendo o processo licitatório a licitação para a seleção do próximo contratado para a prestação de serviço contínuo indispensável. Em havendo uma determinação para que a licitação seja suspensa, não cabe ao gestor optar por licitar ou não, característica das licitações dispensáveis, ele não poderá realizar a licitação para a escolha do contratado, característica própria da inexigibilidade de licitação.

${ }^{2}$ Sobre o tema, o Tribunal de Contas da União também já se manifestou favoravelmente à extensão do contrato além dos 180 dias autorizados pelo legislador (BRASIL, 2010) 


\section{CONCLUSÃO}

Em conclusão é possível aferir que é ilegal a contratação de serviços contínuos com fundamento no artigo 24, inciso IV, nos ditos casos emergenciais.

A justificativa técnica que supostamente fundamentaria a dispensa de ausência de outra solução para o problema é descabida e não pode fundamentar o instituto da licitação dispensável que, como visto, possui contorno de autorização legal e, como tal, não pode ser amoldado ao caso concreto a depender das situações fáticas.

De outro lado, a concepção de uma teoria crítica distintiva da licitação dispensável e da inexigibilidade de licitação permite, facilmente, solucionar o problema fático apresentado.

A inexigibilidade é, como visto, a solução cabível sempre que se apresenta um problema insolúvel de seleção do contratado por licitação. Havendo inviabilidade de competição a inexigibilidade é admitida, posto que não se pode, nem mesmo através da Constituição, obrigar alguém a realizar aquilo que é impossível de ser feito, esta é a máxima por trás da inexigibilidade.

No caso em debate, a competição por meio de processo licitatório é impossível visto que a licitação não foi concluída e o serviço não pode ser interrompido. Assim, enquanto perdurar a situação fática impeditiva do encerramento do certame estará autorizada a contratação por meio da inexigibilidade.

Voltando ao exemplo da ordem judicial suspendendo a licitação para a seleção do próximo contratado para a prestação de serviço contínuo indispensável, firmado o contrato sem licitação, por inexigibilidade prevista no caput do artigo 25 da Lei 8.666/93, para a execução do serviço continuo este contrato poderá ser prorrogado até que a demanda judicial esteja conclusa.

Não há dúvida, no entanto, que, cessada a condição fática autorizadora da inexigibilidade, ou seja, concluído o processo licitatório, no caso em debate, o contrato firmado com fulcro no artigo 25 deverá ser encerrado para dar início ao novo contrato, devidamente licitado, em atendimento ao inciso XXI do artigo 37 da Constituição Federal.

Por fim, é de fundamental importância destacar que a teoria aqui desenvolvida e, sobretudo, a solução proposta ao caso concreto não afasta, em absoluto, a apuração de responsabilidades pela inépcia no planejamento que ensejou a situação em debate. Tal 
apuração independe da solução final dada ao problema, seja ela a dispensa emergencial ou a inexigibilidade.

\section{REFERÊNCIAS BIBLIOGRÁFICAS}

BRASIL. Tribunal de Contas da União. Acórdão no 3238. Relator: Ministro Benjamin Zymler. Diário Oficial da União. Brasília, 2010.

BRASIL. Tribunal de Contas da União. Acórdão n ${ }^{\circ}$ 727. Relator: Ministro Raimundo Carreiro. Diário Oficial da União. Brasília, 2009.

CITADINI, Antonio Roque. Comentários e jurisprudência sobre a lei de licitações públicas. 2. ed. São Paulo: Max Limonad, 1997. 525 p.

FURTADO, Lucas Rocha. Curso de licitações e contratos administrativos. 3. ed. Belo Horizonte: Fórum, 2010. 635 p.

GASPARINI, Diógenes. Direito administrativo. 13. ed. São Paulo: Saraiva, 2008.

MELlO, Celso Antônio Bandeira de. Curso de direito administrativo. 15. ed. São Paulo: Malheiros, 2003. 936 p.

MOREIRA, Egon Bockmann; GUIMARÃES, Fernando Vernalha. Licitação pública: a lei geral de licitação - LGL e o regime diferenciado de contratação - RDC. São Paulo: Malheiros, 2012. 640 p.

MOTTA, Carlos Pinto Coelho. Eficácia nas licitações e contratos: estrutura da contratação, concessões e permissões, responsabilidade fiscal, pregão e parcerias públicas. 10. ed. Belo Horizonte: del Rey, 2005. 1152 p. NIEBUHR, Joel de Menezes. Dispensa e inexigibilidade de licitação pública. 3. ed. Belo Horizonte: Fórum, 2011. $328 \mathrm{p}$.

PEREIRA JUNIOR, Jessé Torres. Comentários à lei das licitações e contratações da administração pública. 8. ed. Rio de Janeiro: Renovar, 2009. 1261 p. 